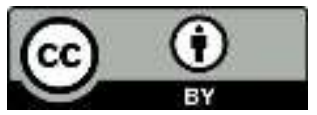

\title{
A EDUCAÇÃO PARA O DIÁlOGO NA PLURALIDADE RELIGIOSA NAS ESCOLAS CONFESSIONAIS
}

\author{
Education for dialogue in religious schools in multiple confessional
}

\author{
Valéria Andrade Leal \\ Mestre em Teologia pela Pontifícia Universidade Católica do Paraná - PUCPR. \\ Graduada em Pedagogia pela mesma Universidade. \\ Assessora de Pastoral Escolar do SAGRADO - Rede de Educação. E-mail: vandradeleal@ yahoo.com.br.
}

RESUMO: O artigo discute o papel da Escola Católica na formação para o diálogo na pluralidade. Parte, sobretudo, de um dos últimos textos da Congregação para Educação católica: Educare al dialogo interculturale nella Scuola Cattolica - Vivere insieme per una civiltà dell'amore. Neste se levanta as vantagens e os perigos da multicultura, a questão dos fundamentalismos e intolerâncias, os diferentes posicionamentos frente à diversidade e a responsabilidade das instituições educativas em educar para a tolerância e a boa convivência. A tarefa de formar para o diálogo e a aceitação do diferente toca à Escola Católica justamente por sua referência aos ensinamentos de Jesus Cristo e pelo seu compromisso social, visto que educar para a boa convivência é uma urgência na sociedade atual.

Palavras-chave: Escola Católica; Diálogo; Diversidade.

ABSTRACT: The article discusses the role of the Catholic school for training in the dialogue in the plurality. Part, especially of one of the last texts of the Congregation for Catholic Education: Educare al interculturale dialogue nella Scuola Cattolica - Vivere insieme per una dell'amore civiltà. This rises the advantages and dangers of multiculturalism, the issue of fundamentalism and intolerance, the different positions on diversity and responsibility of educational institutions to educate for tolerance and coexistence. The task of forming for dialogue and the acceptance of different touches Catholic schools precisely because of its reference to the teachings of Jesus Christ and his social commitment, as educate for coexistence is an urgency in today's society.

Keywords: Catholic School; dialogue; Diversity.. 


\section{Introdução}

Embora possa ter passado despercebido a muitas escolas católicas, no dia 28 de outubro de 2013 houve a veiculação do texto: Educare al dialogo interculturale nella Scuola Cattolica - Vivere insieme per una civiltà dell'amore (sem tradução oficial). O texto soa como uma resposta à realidade hodierna marcada pela pluralidade e a intolerância, por missões de paz e guerras, pela abertura ao diálogo intercultural e por perseguições religiosas. Talvez seja esse o documento da Congregação para Educação Católica - CEC mais lúcido, entre tantos outros, por ser o mais atento à realidade global e ao fato de que a escola católica, especialmente no Brasil, não acolhe apenas católicos, mas estudantes de diversos credos e famílias com diferentes valores.

Educar para a diversidade é tema frequentemente abordado no Brasil. Especialmente a partir da Lei de Diretrizes e Bases da Educação Nacional - LDBEN 9394/96. O tema aparece com expressões emblemáticas como, por exemplo, "respeito à liberdade e apreço à tolerância" (Art. $3^{\circ}$, inciso IV) e ainda "consideração com a diversidade étnico-racial" (Art. $3^{\circ}$, inciso XII). Sobretudo a partir do tema do ensino religioso (Art. 33) a questão da diversidade cultural e religiosa foi amplamente discutida logo após a homologação do texto, conforme aponta Junqueira et al. (2007, p. 31-52).

Não obstante a tantas discussões acerca de temas éticos e culturais, o presente artigo quer refletir sobre a relevância da educação católica para a construção de uma sociedade tolerante e igualitária. Embora muitos pensem que a instituição, Igreja Católica, tenha sido muitas vezes promotora da exclusão e desvalorização de culturas e religiões, a proposta de Jesus de Nazaré, que a inspira, parte do princípio da acolhida e da dignidade de todas as pessoas. $\mathrm{O}$ resgate dos valores verdadeiramente evangélicos na prática educativa católica só pode ter como consequência a capacidade de conviver com o diferente, não apenas compartilhando espaços físicos, mas reconhecendo a dignidade do outro.

\section{A realidade plural}

O referido texto da Congregação para Educação Católica apresenta, já de início, o reconhecimento da diversidade cultural entendida como "grande riqueza quando a partilha equivale a crescimento mútuo" (CEC, intr.). A multiplicidade é entendida como “resultado de uma mistura contínua de comunidades definida como 'mestiçagem' ou 
'hibridação' da família humana no curso da história, o que faz com que não exista uma cultura 'pura' (Ibid., n. 3). Na combinação de conhecimentos, usos e costumes, construiu-se aos poucos as formas de entender o mundo e de entender-se nele enquanto pessoa e comunidade com suas especificidades. A partir desta leitura, reconhece-se as qualidades das diferenças culturais, sobretudo quando possibilitam o encontro e não o "fechamento autorreferencial" (Ibid. n. 1).

O tema da multiculturalidade vem à tona também como consequência do processo de globalização e dos avanços tecnológicos. A partir da economia e da tecnologia, especialmente no campo da comunicação, houve o estreitamento das distâncias geográficas e o contato com diferentes povos, costumes, maneiras de pensar e crer. Igualmente, o fenômeno da imigração é fator que contribuiu, e contribui ainda hoje, para a miscigenação de costumes e crenças, o que é bastante visível de norte a sul do Brasil, desde o colonialismo até os dias de hoje ${ }^{1}$.

Ao mesmo tempo em que é riqueza, a realidade multicultural gera certa preocupação (Ibid., intr.) para governos e também para estudiosos de diversas áreas do mundo inteiro. O mesmo já havia sido apontado por Stavenhagen (in: Delors et al., 1999, p. 246) que entende que a diversidade pode tornar-se um "choque porque põe em questão concepções tradicionais de vizinhança, de comunidade e de nação até aí imutáveis". A diversidade cultural traz ambiguidades, pois ao mesmo tempo em que se caminha para maior capacidade de respeito, de encontro, de partilha, se corre o risco de fechamento pela descomedida exaltação da "singularidade da própria cultura [...] acentuando reações de fundamentalismo e atitudes fechadas de grupos autorreferenciais" (CEC, n. 4). Basta acompanhar os telejornais em que dia a dia são noticiadas guerras por motivos religiosos, perseguições a grupos minoritários, como os yazidis $^{2}$, situações de preconceitos no futebol, no mundo do trabalho, nas escolas. Cresce entre os jovens a adesão a grupos radicais e tribos urbanas que "tendem a acentuar preconceitos e disputas. O espaço da multiplicidade torna-se o espaço da

\footnotetext{
${ }^{1}$ Exemplo claro de um novo processo de imigração para o Brasil pode ser constatado com os altos números de haitianos (in: http://oglobo.globo.com/infograficos/haitianos-no-brasil/), ganeses (in: http://g1.globo.com/rs/rio-grande-do-sul/noticia/2014/07/nova-leva-de-imigrantes-africanos-preocupaautoridades-de-caxias-rs.html) e bengalis (http://atualidadesdodireito.com.br/blog/2014/02/05/brasil-virarota-de-onda-de-imigrantes-bengalis-em-busca-de-refugio/) que procuram melhores condições de vida. Também se pode encontrar europeus fugindo da crise econômica no velho mundo.

${ }^{2}$ Para saber mais sobre os yazidis cf. <http://ihu.unisinos.br/noticias/534276-quem-sao-os-yazidis-alvodos-jihadistas-do-estado-islamico $>$.
} 
intolerância" (LIBÂNIO, 2004, p. 127). Merece atenção, por exemplo, o recrutamento de jovens em países como Inglaterra, França, EUA pelo grupo extremista Estado Islâmico, bem como o resgate de ritualismos e legalismos em movimentos religiosos jovens, inclusive no seio da Igreja Católica.

Da mesma forma, tais ambiguidades ganham espaço no processo de globalização. Diversas culturas e tradições se tornam conhecidas, mas muitas delas, aos poucos, são deixadas de lado. Segundo Stavenhagen (in: Delors et al., 1999, p. 247) "o mundo multicultural tende a uniformizar-se e os valores culturais próprios destes estilos de vida tornam-se, de algum modo, normas internacionais". Juntamente com a democratização de produtos e serviços e a proximidade entre pessoas de diferentes lados do globo, facilitada pelos modernos sistemas de comunicação, são difundidos usos e costumes que vão aos poucos sendo assimilados e tornam-se, por vezes, esmagadores das culturas minoritárias. Isso motiva o Papa Francisco a afirmar:

Em muitos países, a globalização comportou uma acelerada deterioração das raízes culturais com a invasão de tendências pertencentes a outras culturas, economicamente desenvolvidas, mas eticamente debilitadas. Assim se exprimiram, em distintos Sínodos, os Bispos de vários continentes. Há alguns anos, os Bispos da África, por exemplo, retomando a Encíclica Sollicitudo rei socialis, assinalaram que muitas vezes se quer transformar os países africanos em meras "peças de um mecanismo, partes de uma engrenagem gigantesca. Isto verifica-se com frequência também no domínio dos meios de comunicação social, os quais, sendo na sua maior parte geridos por centros situados na parte norte do mundo, nem sempre têm na devida conta as prioridades e os problemas próprios desses países e não respeitam a sua fisionomia cultural". De igual modo, os Bispos da Ásia sublinharam "as influências externas que estão a penetrar nas culturas asiáticas. Vão surgindo formas novas de comportamento resultantes da orientação dos mass-media (...). Em consequência disso, os aspectos negativos dos mass-media e espetáculos estão a ameaçar os valores tradicionais" (EG 62).

É evidente a difusão de padrões de vestir, de comer, de beber, os estilos de música a cantar. Em muitos lugares se nota a imitação dos jovens que não mais querem seguir costumes locais para abraçar padrões estabelecidos pelas telas de cinema. Muitas vezes tais mudanças são motivadas por propagandas que visam vender produtos ampliando mercados para grandes multinacionais. Outras vezes, tratam-se de interesses políticos, de dominação e subjugação cultural.

Neste contexto a pluralidade de crenças é uma das marcas da diversidade. Para a CEC (n. 8), as religiões objetivam dar respostas a questões existenciais do ser humano, 
o que "necessariamente coloca as religiões não apenas em diálogo entre si, mas também com as várias formas de interpretação ateias ou não religiosas da pessoa humana e da história, ao ser confrontado com as mesmas perguntas sobre o sentido". Por caminhos diferentes, todas as religiões buscam chegar à mesma meta, logo os pontos de convergências são mais números do que as divergências. Assim, o diálogo entre os diferentes grupos religiosos se faz urgente e necessário para evitar "reducionismo e instrumentalização" da fé, bem como julgamentos que desqualificam as crenças diferentes.

Além da questão do diálogo entre as religiões, entre em cena a relação das religiões com formas de pensamento não baseadas na fé. A CEC (n. 9) denuncia que a secularização, ou mesmo certo laicismo, corre o risco de marginalizar não apenas algumas religiões, mas a própria experiência religiosa relegando-a a esfera da vida privada, sem voz no âmbito público. Ora, para que a religião possa contribuir para o diálogo na diversidade é preciso que seja reconhecida enquanto fenômeno humano, dado antropológico que pode iluminar e enriquecer a razão científica. Além de dado cultural, as religiões são responsáveis pela formação de consciências e exatamente por isso podem tornar-se instrumentos de propagação dos valores humanos, da tolerância e do respeito. Cabe também um debate amadurecido entre a fé e a razão científica (CEC, n. 11).

\section{Motivações para a educação para o diálogo}

Em meio a esta realidade encontram-se instituições educativas dentre as quais destaca-se as confessionais católicas. Enquanto educativa, tem a responsabilidade de formar cidadãos capazes de conviver harmoniosamente em sociedade e de transmitir o legado cultural das gerações anteriores. Como parte da Igreja Católica, compartilham seus valores e conceitos e são partícipes da missão de evangelizar entendida como a razão de ser da Igreja (Cf. EN 5). Sendo assim, é importante considerar as motivações de tal instituição para o diálogo:

A clareza do diálogo comporta, antes de tudo, a fidelidade à identidade cristã. "Os cristãos apresentam Jesus de Nazaré. Ele é, acreditamos, o Logos eterno, que se fez carne para reconciliar o homem com Deus e revelar o sentido último de todas as coisas. É ele quem levamos para o fórum do diálogo inter-religioso. $\mathrm{O}$ desejo ardente de seguir seus passos estimula os cristãos a abrirem suas mentes e corações ao diálogo (cf. Lc 10,25-37, Jo 4,7-26)". A Igreja 
Católica proclama que "Jesus Cristo tem, para a humanidade e sua história, significado e valor singular e único, e somente Ele, exclusivo, universal e absoluto. Jesus é verdadeiramente o Verbo de Deus feito homem para a salvação de todos" (CEC, n.16).

Partindo desta crença, a Igreja Católica entende que suas instituições educativas são lugares adequados para a educação ao diálogo justamente por partirem de uma "concepção cristã da realidade" (CEC, n. 16) que coloca a pessoa humana no centro. Sendo assim, busca-se maior consciência da própria identidade cultural e religiosa e o conhecimento de outras religiões para se estabelecer um diálogo verdadeiro (CEC, n. 18). Assim, "os professores têm a responsabilidade de respeitar sempre a pessoa humana que procura a verdade de seu próprio ser; de apreciar e divulgar as grandes tradições culturais abertas à transcendência e que expressam o desejo de liberdade e verdade" (Ibid.). Esse respeito se dá justamente no contato com outras culturas e crenças. Como modelo, o Papa Francisco apresenta uma escola jesuíta da Albânia póscomunismo, em que a retomada das atividades se deu

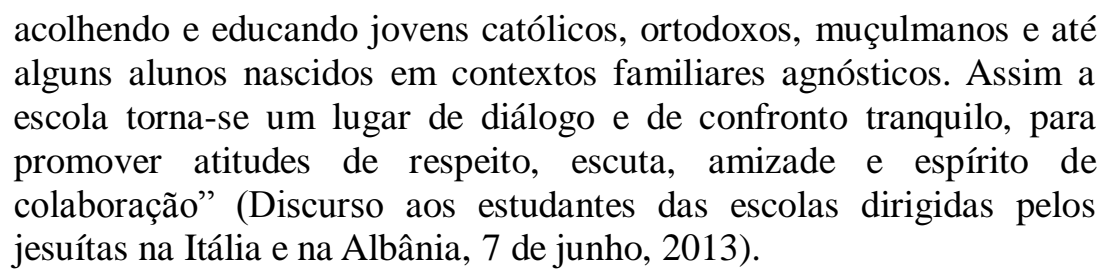

Neste exemplo, destaca-se a convivência entre diversos jeitos de crer e entender o mundo neste contexto em que todos deveriam estar unidos na reconstrução do país. Trata-se da prática do diálogo e da tolerância e não apenas teorias de como promovêlos. A escola, neste circunstância pode oferecer um conhecimento que impulsiona a “viver juntos e construir uma civilização do amor" (CEC, n. 20).

A CEC reconhece que a diversidade está dentro da escola. Nela há diversas formas de crer, diferentes modelos de famílias alicerçados em diferentes valores, adeptos de diferentes partidos políticos, descendentes de diferentes raças. Para fundamentar a educação para o diálogo, são expostos argumentos teológicos, antropológicos e pedagógicos.

Quanto aos aspectos teológicos o texto em questão aponta para a condição da pessoa humana enquanto imagem e semelhança de Deus Trindade (CEC, n. 34). Nesta ótica, homem e mulher de todas as raças são chamados a viver em comunhão, tal como é a comunhão trinitária. A partir desta concepção surge a compreensão da humanidade 
como "única família humana, baseada na solidariedade e nos valores fundamentais da justiça e da paz” (Ibid., 37). Em paralelo, surge, no âmbito da globalização a ideia de "aldeia global" que destaca a proximidade entre as pessoas e também pode indicar certo anseio por comunhão. Mesmo para os que não creem, tal concepção abre para o diálogo não apenas como estratégia política, mas como verdadeiro reconhecimento da dignidade do outro.

Na perspectiva antropológica, parte do princípio de que o diálogo se dá a partir do encontro com pessoas concretas e que neste encontro "culturas ganham vida e se reformulam uma a outra a partir deste encontro com o outro" (CEC, n. 38). Com esta afirmação fica confirmada a compreensão de diversidade como riqueza que amplia os horizontes de todas as partes envolvidos. Ora, tal reconhecimento pressupõe uma atitude humilde de quem sabe que pode aprender com o outro, reconhecer suas qualidades e também partilhar o próprio conhecimento.

A natureza relacional do ser humano também é um aspecto antropológico considerado no texto (CEC, n. 38-39). Sem essa consciência, o homem e a mulher caem na solidão, considerado um grande mal, pois é fonte de alienação, uma vez que há o fechamento em si mesmo. Mais uma vez se reafirma a pertença a uma só família humana, o que contribui com o desenvolvimento dos povos. Assim, na base das trocas culturais está a capacidade de estabelecer relação e entender-se a partir do confronto com o outro, do amor dado e recebido, pois, "as relações alcançam sua natureza mais profunda se estão baseadas no amor recebido como, por sua vez, na capacidade de dar amor" (CEC, " (CEC, n.39). O amor é entendido como saída do egoísmo, o "cuidado do outro e pelo outro" (DCE 6) que torna real a fraternidade humana.

O amor é a verdadeira nobreza da pessoa, além da sua pertença étnica ou cultural ou patrimonial e além da posição social. Ele é o vínculo mais forte, autêntico e aceito que une os homens entre si e que lhes permite ouvir ao outro, dar-lhe a atenção e o apreço que merece (CEC, n. 41).

O amor é a verdadeira nobreza da pessoa, além da sua pertença étnica ou cultural ou patrimonial e além da posição social. Ele é o vínculo mais forte, autêntico e aceito que une os homens entre si e que lhes permite ouvir ao outro, dar-lhe a atenção e o apreço que merece.

Com base nos fundamentos teológicos e antropológicos se ressalta a centralidade da pessoa humana enquanto relacional para então lançar as bases pedagógicas de uma 
educação para o diálogo. Desta forma, a relacionalidade é a base para um paradigma pedagógico considerado essencial para o desenvolvimento da pessoa humana.

Tal concepção guia uma ideia de diálogo não abstrata ou ideológica; mas sim, forjada no respeito, na compreensão e serviço mútuos. Ele se baseia na ideia de cultura historicizada e dinâmica, enquanto se recusa a condenar os outros a uma espécie de prisão cultural. Finalmente, a consciência reside no fato de que a relatividade das culturas não significa relativismo (o qual, apesar de que respeita as diferenças, distancia as culturas ao seu mundo autônomo, considerando-as fechadas e impenetráveis); ao contrário, busca por todos os meios alimentar uma cultura de diálogo, de concordância e transformação mútua, a fim de alcançar o bem comum (CEC, n. 42).

Desta compreensão de que a dignidade da pessoa está no centro da discussão e não exatamente sua cultura, é possível partir para uma aceitação do outro com profundo respeito pelo seu ser, suas opiniões, valores e crenças, pois o outro não é visto como instrumento de certos valores e ideias, mas com dignidade e valor. Assim, o diálogo acontece de forma autêntica, pois sabe-se que todas as partes podem expressar livremente seu ponto de vista.

\section{O que compete à escola católica}

Aplicar estes conceitos na escola é desafio que se soma à necessidade de unir todas as forças para superar as divisões e preconceitos geradores de exclusão e violência. Na escola católica, em especial, trata-se de uma urgência implícita à sua própria natureza de testemunha dos gestos e palavras de Jesus de Nazaré. Para tanto, mais do que conceitos a serem ensinados, o fundamento é uma prática educativa de acolhida e que favoreça o reconhecimento da própria identidade e o valor das diversas identidades em seu seio.

Neste processo educativo, o interesse por uma convivência pacífica e enriquecedora deve basear-se no conceito mais amplo de ser humano, caracterizado por uma busca contínua de autotranscendência, vista não apenas como movimento psicológico e cultural, para além de qualquer forma de egocentrismo e etnocentrismo, mas também como um impulso espiritual e religioso, de acordo com uma concepção de desenvolvimento integral e transcendente da pessoa e da sociedade (CEC, n. 45).

$\mathrm{Na}$ base desta prática pedagógica está o amor entendido como “dom e reciprocidade" (CEC, n. 47) no duplo movimento de dar e receber. A escola é espaço de convivência, de novas relações, de ampliar os horizontes. Tudo isto se dá na relação 
professor-estudante, estudante-estudante, estudante-culturas e conhecimento. Logo é lugar propício para trafegar nesta via de mão dupla, de saída de si em direção ao outro. Trata-se de uma "pedagogia de comunhão" (Ibid.).

Para tanto, há que se cultivar no ambiente escolar o "espírito de unidade" (CEC, n. 49) que busca o bem comum e ultrapassa o legalismo e o fundamentalismo, mas usa de todos os meios para colocar "todos na condição de reciprocidade para ser cidadãos conscientes e responsáveis" (Ibid.). Na prática pedagógica, isso se concretiza na medida em que conteúdos e exemplos reconhecem e valorizam as diferentes culturas promovendo a interação entre elas sem desqualificar nem descaracterizar qualquer que seja.

Numa perspectiva pedagógica e intercultural, o mais belo que a educação católica pode trazer para a escola é o testemunho do contínuo, íntimo entrelaçamento vivido entre identidade e alteridade, em sua dinâmica harmonia nas diferentes relações entre os adultos (professores, pais, educadores responsáveis das instituições...), entre professores e alunos, entre os alunos uns com os outros, sem prejuízo do respeito em relação a cultura, gênero, classe social ou religião (CEC, n. 50).

Neste espaço privilegiado de formação da consciência em que o educador é mediador das diversas relações estabelecidas, educar para o diálogo implica também conscientizar acerca da própria identidade, pois a verdadeira conversação se dá a partir do conteúdo que cada um traz e não da anulação dos argumentos de outrem. Assim, trata-se também de valorizar a própria origem e cultura, sem deixar-se desvalorizar em sua própria condição humana considerando aspectos de outros grupos mais importantes que os seus, o que muitas vezes é fomentado pela ocidentalização. Não é possível reconhecer de forma real a riqueza do outro, quando não se reconhece a própria riqueza. É a lógica do "amar o próximo como a ti mesmo" (Mt 22,39) e "conhece-te a ti mesmo".

Assim como na sociedade os diversos grupos tem, por vezes, dificuldades para compreensão mútua, o mesmo pode ocorrer dentro da escola. Ao mesmo tempo, para a escola cada estudante traz as dores do preconceito, da exclusão. Na escola também, se entra em contato com a história de etnias inteiras que foram perseguidas e marginalizadas, e alguns estudantes pertencem a muitos desses grupos. Em meio a situações e histórias de intolerância e violência cabe à escola católica a "coerência no doar-se a si mesmo, na capacidade de pedir e conceder o perdão, não por exibicionismo 
ou falso moralismo, mas 'por amor' - para contribuir com o desenvolvimento do mundo" (CEC, n. 54). Ao mesmo tempo, cada um deve ser educado a lutar por seus direitos e garantir seu espaço na sociedade não pela desvalorização do outro, ou como uma reação de vingança, mas convencido de sua dignidade e capacidade de contribuir para o bem de todos.

A escola católica, com sua referência explícita à pessoa de Jesus de Nazaré e a centralidade na pessoa humana (CEC, n. 57) intenta ser um laboratório de interculturalidade. O clima de diálogo e respeito, livre de fundamentalismos e de relativismos será a marca de uma verdadeira comunidade educativa. Como o próprio documento expressa:

A escola-comunidade é lugar de encontro, promove a participação, o diálogo com a família que é a primeira comunidade a que pertencem os alunos; sempre respeitando a sua cultura e colocando-se em atitude de profunda escuta das necessidades que encontra e as expectativas que lhe são dirigidas. Trabalhando assim, ela pode ser considerada um verdadeiro laboratório de interculturalidade, mais que proclamada, vivida (CEC, n. 58).

Isso significa que as relações estabelecidas entre as pessoas e com o conhecimento vão sempre em direção à valorização e enriquecimento mútuos. Ao mesmo tempo em que é tarefa, é desafio constante para a escola católica manter um ambiente de liberdade, visto que a atitude ouvinte é tarefa de cada uma das pessoas envolvidas no processo e que juntas convivem na instituição escolar. Para tanto, precisa unir todas as forças para que este escopo não seja apenas um belo discurso, mas se faça sentir em todos os espaços. A formação e conscientização de bons profissionais da educação são urgências e responsabilidade das instituições. Ao mesmo tempo, a escola católica conta com as famílias, promovendo sua participação e "formas de corresponsabilidade" (CEC, n. 59).

Grande importância tem igualmente o projeto educativo da escola. Este precisa estar aberto à pluralidade e às diferenças culturais para que haja um processo de reflexão-ação cujo foco seja a formação integral em que "estudos e vida convergem e se fundem harmoniosamente" (CEC, n.62). Para a construção do projeto educativo a CEC (n. 63) propõe como linhas de trabalho: a identidade da escola católica que tem os ensinamentos de Jesus como fundamento; a intenção de construir um horizonte comum; a abertura para a universalidade mediante sólidos conhecimentos; a formação de 
identidade fortes capazes de dialogar a partir do que são; o desenvolvimento da autorreflexibilidade; o respeito e compreensão dos valores de outras culturas; a formação para a participação e responsabilidade social. Com base nestes princípios é possível construir uma proposta pedagógica que atenda à realidade diversificada da própria escola.

Da mesma forma, o currículo da escola católica fundamenta-se na centralidade da pessoa e a partir disso, as disciplinas se apresentam como meios de promover a integridade de todas as pessoas em suas culturas. Nesta perspectiva, "os conteúdos não são indiferentes, nem são indiferentes o modo de apresentá-los” (CEC, n. 65), mas tudo converge para a promoção do diálogo e do respeito mútuo. Busca-se um conhecimento que se torne sabedoria de vida (Ibid., n.66) porque tenha como ponto de partida os valores e o compromisso de ser cidadão. Por isso, o currículo precisa busca constante interação entre teoria e prática, entre discurso e ação, conhecimento e atitudes.

O texto da CEC (Conclusão) termina ressalta a necessidade de uma nova consciência acerca da dimensão multicultural evitando fundamentalismos e relativismos. Insiste que para promover o diálogo não há que se abrir mão da própria identidade, mas sim apresenta-la com humildade e saber acolher a identidade do outro como riqueza que pode contribuir com a sociedade de igual maneira.

Diante do exposto, entende-se que a tarefa da escola, especialmente a católica, uma vez que declara a condição de "imagem e semelhança" da humanidade, é educar para um profundo respeito que tem raízes na admissão de o outro é igual em nobreza de em valores e crenças, mesmo quando há pontos que não confluem. Logo, deve ser ela mesma lugar de confluência de ideias, de discussão de opiniões e de respeitosa divergência quando os pontos são conflituosos. É lugar de exercitar a boa convivência para ser instrumento da paz.

\section{Considerações}

Diante da realidade multicultural, não é possível, ou melhor, cabível, permanecer indiferente. $\mathrm{O}$ processo de humanização, a que toda pessoa é chamada a percorrer exige uma tomada de posição frente ao outro, ao diferente, ao desconhecido e misterioso que é cada ser humano. Este não é, pois, um percurso que se faz sozinho, mas toda a sociedade é responsável por deixar às novas gerações os valores humanos 
que a fizeram sobreviver e prosperar ao lado de outras formas de ver e entender o mundo, respeitando-a e enriquecendo-se com este convívio.

A instituição escola tem papel fundamental neste processo, pois ela é uma das grandes responsáveis pela transmissão da cultura das sociedades ao mesmo tempo em que pode gerar novos conhecimentos e oportunidades de reflexão. Particularmente a Escola Católica, uma vez que entende sua missão educativa à luz dos ensinamentos de Jesus de Nazaré tem o compromisso urgente de promover a boa convivência visto que a acolhida às diferenças aparece em diversos momentos nas narrativas evangélicas. Seja por convicções religiosas ou responsabilidade social, a escola confessional tem a possibilidade de educar para uma boa convivência superando os próprios preconceitos para reconhecer a verdadeira dignidade do outro e viver com seriedade o princípio do amor herdado do Mestre.

A educação para o respeito à diversidade se faz pelo ensinamento, mas principalmente pela prática transformadora de ser escola acolhedora, respeitosa e tolerante, que sabe colocar-se em atitude de diálogo. Diálogo implica em ouvir e falar, em apreender, avaliar e sintetizar. Logo, o diálogo a ser vivido e ensinado na escola parte da humildade de quem se reconhece aprendiz na escola da vida, de quem sabe que o outro também traz consigo sua gama de experiências, de valores, de virtudes que podem ser partilhadas para a construção da paz e da boa convivência. A Escola confessional Católica cumprirá sua missão quando libertar-se da pretensão de ser herdeira de uma tradição mais rica e considerável que as demais e colocar-se ao lado dos outros para a concretização dos ideais de solidariedade e igualdade defendidos e desejados por todos..

\section{Referenciais}

BRASIL. Senado Federal. Lei de Diretrizes e Bases da Educação Nacional: no 9394/96. Brasília: 1996.

CONGREGAÇÃO PARA EDUCAÇÃO CATÓLICA. Educare al dialogo interculturale nella Scuola Cattolica. Vivere insieme per una civiltà dell'amore. Disponível em: http://www.vatican.va/roman_curia/congregations/ccatheduc/documents/rc_con_ccatheduc_doc 20131028_dialogo-interculturale_it.html. Acesso em: 04 set. 2014.

DELORS, Jacques (coord.) et al. Educação: um tesouro a descobrir. Relatório para a UNESCO da Comissão Internacional sobre Educação para o sécu1o XXI. São Paulo: Cortez; Brasília: MEC; UNESCO, 2002. 
ALBÂNIA.

Disponível

em:

<http://w2.vatican.va/content/francesco/pt/speeches/2013/june/documents/papa-

francesco_20130607_scuole-gesuiti.html>. Acesso em: 15 ago. 2014.

IGREJA CATÓLICA. Papa (2005-2013: Bento XVI). Carta encíclica Deus Caritas est: sobre o amor cristão. Disponível em: <http://www.vatican.va/holy_father/benedict_xvi/encyclicals/documents/hf_benxvi_enc_20051225_deus-caritas-est_po.html>. Acesso em: 16 abr. 2013.

IGREJA CATÓLICA. Papa (2013- : Francisco). Exortação Apostólica Evangelii Gaudium. Disponível em:

$<$ http://www.vatican.va/holy father/francesco/apost exhortations/documents/papafrancesco_esortazione-ap_20131124_evangelii-gaudium_po.html\#II>. Acesso em: 15 jan. 2014. IGREJA CATÓLICA. Papa (1963-1978: Paulo VI). Carta encíclica Evangelii Nuntiandi: sobre a evangelização no mundo contemporâneo. Disponível em: <www.vatican.va/holy_father/paul_vi/apost_exhortations/documents/hf_pvi_exh_19751208_ev angelii-nuntiandi_po.html>. Acesso em: 17 mai. 2010.

JUNQUEIRA, S.R.A.; CORREAA, R.L.T.; HOLANDA, A.M.R. Ensino Religioso. Aspectos legal e curricular. São Paulo, Paulinas: 2007.

LIBÂNIO, João Batista. Jovens em tempo de pós-modernidade. Considerações socioculturais e pastorais. São Paulo: Loyola, 2004.

Recebido: $17 / 04 / 2014$

Received: 04/17/2014

Aprovado: 19/07/2014

Approved: 07/19/2014 